\title{
Evaluation of the impact of wood combustion on benzo(a)pyrene concentrations, using ambient air measurements and dispersion 5 modelling in Helsinki, Finland
}

Hellén H. ${ }^{1}$, Kangas L. ${ }^{1}$, Kousa A. ${ }^{2}$, Vestenius M. ${ }^{1}$, Teinilä K. ${ }^{1}$, Karppinen A. ${ }^{1}$, Kukkonen, J. ${ }^{1}$ and Niemi J.V. ${ }^{2,3}$

10

\footnotetext{
${ }^{1}$ Finnish Meteorological Institute, P.O. Box 503, FI-00101 Helsinki, Finland

${ }^{2}$ Helsinki Region Environmental Services Authority, P.O. Box 100, FI-00066 HSY, Helsinki, Finland

${ }^{3}$ Department Environmental Sciences, University of Helsinki, P.O. Box 65, FI-00014 University of Helsinki, Finland
}

Correspondence to: Heidi Hellén (heidi.hellen@fmi.fi)

20 Supplement figures S1 and S2 show the monthly variation of BaP and levoglucosan concentrations at different stations in Helsinki metropolitan area together with monthly mean temperatures at Kumpula weather station in Helsinki in 2007-2015. 

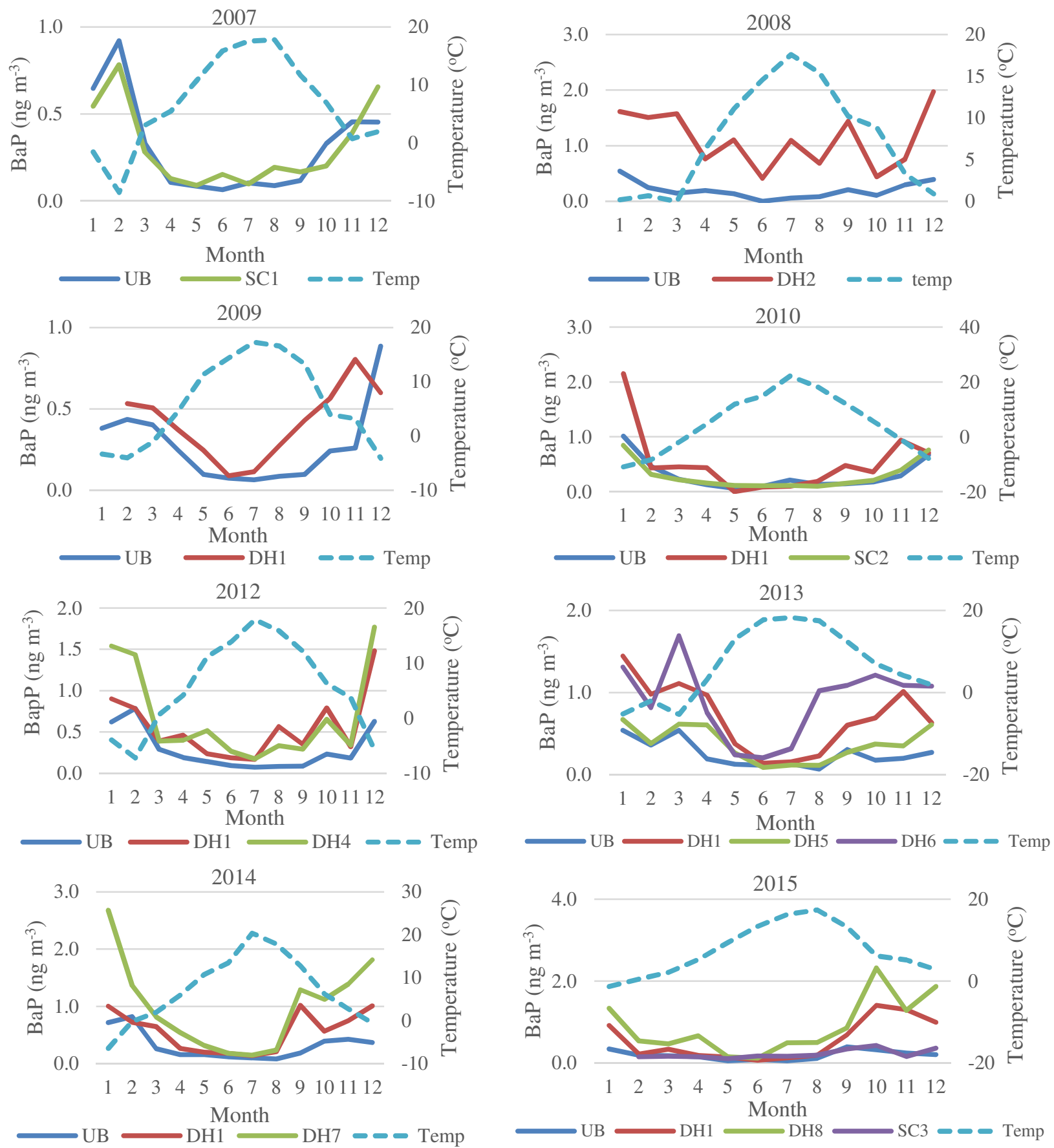

5 Figure S1. Measured monthly means of BaP concentrations at different stations in different years in Helsinki metropolitan area togethet with mean temperatures at Kumpula weather station in Helsinki 

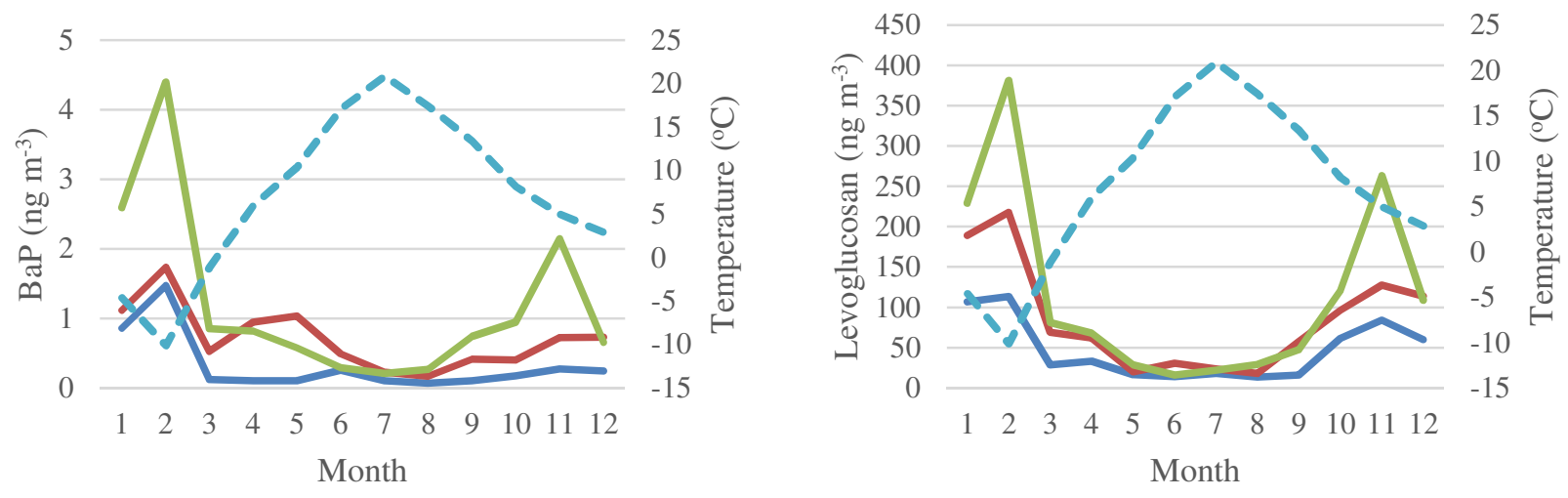

$\longrightarrow \mathrm{UB} \longrightarrow \mathrm{DH} 1 \longrightarrow \mathrm{DH} 3-\infty$ Temp

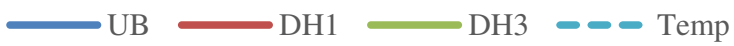

Figure S2. Measured monthly mean concentrations of $\mathrm{BaP}$ and levoglucosan at different stations in Helsinki metropolitan area 5 in 2011 together with temperature from Kumpula weather station in Helsinki. 